\title{
Type 2 diabetes and healthcare resource utilisation in the Kingdom of Bahrain
}

\author{
Rabha AbdulAziz Salman', Adel Salman AlSayyad² and Craig Ludwig ${ }^{3^{*}}$ (D)
}

\begin{abstract}
Background: Type 2 diabetes is a growing health challenge in the Kingdom of Bahrain, and the disease exerts significant pressure on the healthcare system. The aim of this study was to assess the annual costs and understand the drivers of those costs in the country.

Methods: A sample of 628 patients diagnosed with type 2 diabetes were randomly selected from primary healthcare diabetes clinics, and the direct medical and indirect costs due to type 2 diabetes were analysed for a one-year period. The study used patients' medical records, interviews and standardised frequency questionnaires to obtain data on demographic and clinical characteristics, complication status, treatment profile, healthcare resource utilisation and absenteeism due to diabetes. The indirect costs were estimated by using the human capital approach. The direct medical and indirect costs attributable to type 2 diabetes were extrapolated to the type 2 diabetes population in Bahrain.

Results: In 2015, the total direct medical cost of type 2 diabetes was 104.7 million Bahraini dinars (BHD), or 277.9 million US dollars (USD), and the average unit cost per person with type 2 diabetes (1162 BHD, or 3084 USD) was more than three times higher than for a person without the condition (372 BHD, or 987 USD). The healthcare costs for patients with both micro- and macrovascular complications were more than three times higher than for patients without complications. Thus, $9 \%$ of the patients consumed $21 \%$ of the treatment costs due to complications. Complications often lead to hospital admission, and $20 \%$ of the patients consumed almost $60 \%$ of the healthcare costs attributable to type 2 diabetes due to hospital admissions. The indirect cost due to absenteeism was 1.23 million BHD (3.26 million USD).
\end{abstract}

Conclusion: Type 2 diabetes exerts significant pressure on Bahrain's healthcare system - primarily due to costly diabetes-related complications. It is therefore important to optimise the management and control of type 2 diabetes, thereby reducing the risk of disabling and expensive complications.

Keywords: Type 2 diabetes, Healthcare resource utilisation, Direct costs, Indirect costs, Micro- and macrovascular complications

\section{Background}

Diabetes is a serious disease and a growing public health challenge in every part of the world [1]. The International Diabetes Federation (IDF) estimates that currently 425 million adults have diabetes globally and expects this number to increase to 629 million by 2045 [2].

There are two primary forms of diabetes, which are more often than not grouped together, but the causes and costs of which are different. Type 1 diabetes is an

\footnotetext{
* Correspondence: cl@last-mile.dk

${ }^{3}$ Last Mile, Holte, Denmark

Full list of author information is available at the end of the article
}

autoimmune disease [2] and is estimated to account for $10-15 \%$ of cases [3-5]. People with type 1 diabetes require insulin to survive [2]. Despite being largely preventable, type 2 diabetes (T2D) accounts for about $90 \%$ of cases [6-8]. In T2D, the body is able to produce insulin but becomes resistant so that the insulin is ineffective. Over time, insulin levels may subsequently become insufficient. Both the insulin resistance and deficiency lead to high blood glucose levels [2]. If blood glucose levels continue to rise due to the diabetes not being well controlled, the risk of serious and morbid complications

(c) The Author(s). 2019 Open Access This article is distributed under the terms of the Creative Commons Attribution 4.0 International License (http://creativecommons.org/licenses/by/4.0/), which permits unrestricted use, distribution, and 
increases [9]. For example, diabetes is the primary cause of renal failure, amputation and vision loss [10].

The healthcare costs of diabetes are substantial and include expenditure on resources used for treating the condition, such as outpatient consultations, diagnostic testing, medications, emergency visits and inpatient procedures and care [11]. Globally, 727 billion USD, or 12\% of direct healthcare expenditures, was spent on diabetes in 2017, and this figure is projected to reach 776 billion USD by 2045 [2].

From other countries where research into the economic burden of diabetes exists, it is evident that a substantial portion of direct healthcare expenditure is driven by complications related to diabetes. In the US, the American Diabetes Association (ADA) estimated that the total cost of diagnosed diabetes in 2017 was 327 billion USD, including 237 billion in direct medical costs and 90 billion in reduced productivity [12]. Prescription medications for the treatment of diabetes-related conditions like hypertension and cardiovascular disease accounted for $30 \%$ of the total direct medical expenditure while another 30\% was due to admissions [12].

In France, Charbonnel et al. found that the average medical expenditure for a person with T2D was 6506 EUR (7205 USD) in 2013, accounting for 8.5 billion EUR (9.4 billion USD) of the country's medical costs [13]. Furthermore, they identified the highest individual direct costs incurred were related to admissions at $33.2 \%$ of total costs [13]. Similarly, in Italy, a study from 2014 noted that the most important contributor to direct costs was admissions, which accounted for almost 53\% of the total 9.6 billion EUR [14]. In the UAE, using a macro cost approach, Al-Maskari et al. estimated the annual direct cost of diabetes to be around 1605 USD for patients without complications, with the values increasing significantly with the addition of complications [15].

Though, in general, lower than the direct costs, the indirect costs associated with diabetes - the value of the loss in productivity due to morbidity and mortality - are also considerable [11, 16, 17]. However, indirect costs are challenging to estimate, and the variation across studies is high.

The Gulf Cooperation Council (GCC) countries (Bahrain, Kuwait, Oman, Qatar, Saudi Arabia and the United Arab Emirates) are part of the Middle East and North Africa (MENA) region, which currently has the world's second-highest age-adjusted comparative diabetes prevalence: $10.8 \%$ [2]. If current trends continue, the number of people with diabetes in the region is expected to increase by $72 \%$ by 2045 [2]. The main drivers for the steep rise in these countries are major demographic and socioeconomic transitions and parallel shifts in culture, lifestyle and dietary habits, together with increased life expectancy and genetic predisposition to T2D [18]. In addition, it has been shown that more than $70 \%$ of people with diabetes in MENA countries have poorly controlled diabetes [19], leading to high rates of complications. Thus, the pressure on countries' healthcare budgets in this region is high and, proportionally, the region has the highest percentage of healthcare budget spent on diabetes, at close to $17 \%$ in 2017 [2]. The diabetes cost in the MENA region was estimated at 21 billion USD in 2017 and is expected to increase to 36 billion USD by 2045 [2].

In Bahrain, a national health survey revealed an overall prevalence of T2D of $14.3 \%$ among Bahraini nationals in the age group 20-64 [20] - the age group considered to be the most important for social and economic productivity. According to the IDF, diabetes healthcare expenditure in Bahrain was 86 BHD (227 million USD) in 2015, translating to a unit cost per person with diabetes of 555 BHD (1473.50 USD) [21]. This is a more than sixfold increase in just 12 years, up from 14 million BHD (37 million USD) in 2003 [21, 22]. However, IDF estimates of diabetes costs in GCC countries have been shown to underestimate the actual costs [23], and the impact of diabetes on Bahrain's healthcare budget and overall economy is thought to be far greater than the figures reported by the IDF. Back in 2017, the IDF significantly increased its estimate of diabetes-related healthcare expenditure in Bahrain to 110 million BHD (292 million USD), or a unit cost per person with diabetes of 667 BHD (1769.9 USD) [2].

Research into the economic burden of diabetes, and specifically that of T2D in Bahrain and other GCC countries, is lacking. Such research is required to guide decisionmakers towards initiating disease prevention and management strategies that can prevent future healthcare budgets 'drowning' under the pressure of diabetes. To our knowledge, this is the first cost-of-illness study estimating the healthcare costs of T2D in Bahrain to include the costs of direct management of diabetes and diabetes-related micro- and macrovascular complications as well as absenteeism due to T2D as a proxy for indirect costs.

\section{Methods}

\section{Aim, design and setting}

The study used a prevalence-based cost-of-illness approach, and data were collected between March 2011 and December 2012 to cover a one-year period for each recruited patient. Patient recruitment and data collection were performed in primary healthcare diabetes clinics.

The Kingdom of Bahrain has a comprehensive healthcare system organised around a network of primary health centres, secondary care hospitals and tertiary care centres. Treatment and care for people with T2D are primarily managed through 28 primary health centres distributed across the five regions of the country. The 
centres are geographically located so that there is a health centre within a 20-min drive of all residents' homes. Each centre has laboratory facilities, a theatre for minor surgery, general and diabetes clinics, maternal and child health and physiotherapy departments, primary care physicians, diabetologists, general and diabetes nurses, health educators, social workers and physiotherapists.

All health centres use electronic files and are networked with each other and with the main hospitals. Diabetes clinics are run by a diabetologist and a diabetes nurse, and they are where newly diagnosed and/or uncontrolled diabetes cases are referred for assessment, management and education. Diabetologists in these clinics can prescribe every range of antidiabetic medicine in addition to glucometers and strips. Patients are then referred back to their general practitioner (GP) in the same health centre for routine follow-up.

Generally, only very advanced cases of T2D - those requiring specialist consultation - are referred to a secondary care facility. Other types of diabetes, such as type 1 diabetes and gestational diabetes, are seen at secondary healthcare facilities.

In 2012, the year of data collection, healthcare services were provided free of charge to Bahraini nationals, and some people were covered by insurance through their employers.

\section{Characteristics of participants or description of materials}

Participants were selected using multi-stage stratified cluster sampling. Nine primary healthcare diabetes clinics were randomly selected, and the sample size was divided among these. The sample size for each clinic was proportional to the catchment area. Participants were selected by systematic random sampling (every 10th patient) from the clinics' registries. The study participants included male and female Bahraini nationals with T2D between the ages of 20 and 64 .

The required sample size for a prevalence study of T2D was calculated as:

$$
N=\frac{F p(1-p)}{d^{2}}
$$

where $\mathrm{N}$ is the sample size, $\mathrm{F}$ is 10.51 (power of $90 \%$ and significance of $95 \%$ ), $\mathrm{P}$ is $17.5 \%$ (expected proportion in population based on previous studies is $15-20 \%$ ) and $d$ is $2.5 \%$ (smallest effect of interest). Furthermore, taking into account a non-response rate of $25 \%$ and a prevalence of T2D of $15-20 \%$, the required sample size is 455-607 subjects. Complete data on 628 people with T2D were obtained and analysed. Interviews and a standardised frequency questionnaire, specifically developed for this study (Additional file 1), were completed to obtain data on demographics, healthcare resource utilisation, healthcare provider, health insurance status and impact on work in the form of absenteeism due to T2D in the previous 12 months. Clinical information regarding T2D, its complications and the treatment profile of participants was based on the patients' medical records. Diabetesrelated complications were grouped by microvascular complications (nephropathy, peripheral neuropathy and retinopathy) and by macrovascular complications (ischaemic heart disease, cerebrovascular accidents or transient ischaemic attacks and peripheral vascular disease).

\section{Data analysis}

The direct medical costs related to T2D were classified into seven resource categories: admissions, procedures (cardiac catheterisation, laser treatment and cataract surgery), outpatient $(\mathrm{OP})$ visits (primary healthcare and secondary healthcare), laboratory tests, oral antidiabetic medicine, other oral medicine used to treat comorbidities, insulin and other injectables, and self-monitoring (glucometer device and strips). A bottom-up approach was used to estimate the total medical cost for each patient as the unit cost for each resource used multiplied by the total resources used. The cost of each resource item was obtained from a 2015 internal document provided by the Supportive Services Directorate of Bahrain's Ministry of Health (MOH) [24]. Thus, the cost calculations relate to the year 2015. Healthcare services provided to people with diabetes remained unaltered between 2012 and 2015. The average cost for each patient per year was applied to all people with T2D in Bahrain. The direct medical costs were calculated for people with T2D without complications, for people with T2D and microvascular complications, for people with T2D and macrovascular complications, and for people with T2D and both micro- and macrovascular complications. The indirect costs of T2D were approximated by productivity losses due to absenteeism related to T2D. We used the human capital approach, where days absent were multiplied by average earnings per capita per day [25]. According to the Labour Market Regulatory Authority of Bahrain, the average daily wage was 24.9 BHD $\left(66.1 \mathrm{USD}^{1}\right)$ in 2015 [26].

The overall number of people with T2D in Bahrain was used to extrapolate the cost estimates for the study sample to a population estimate. The number of people with T2D in Bahrain was estimated to be 90,110, based on a population size of 1.3 million in 2015 and a prevalence of T2D of $14.3 \%$ among Bahrainis [20] and of $6.2 \%$ among non-Bahrainis [27] for the 20-64 age group. T2D

${ }^{1}$ Currency converter: 1 BHD $=2.6542$ USD on 31 December 2015. https://www.currency-converter.org.uk/currency-rates/historical/table/ BHD-USD.html. 
costs were assumed to be similar for Bahrainis and nonBahrainis.

The research was approved by the $\mathrm{MOH}$, and an informed consent for agreement to participate in the study was obtained from all study participants.

\section{Analysis}

Descriptive statistics were used to describe continuous variables, and frequencies were used to describe categorical variables.

\section{Results}

\section{Demographic and clinical characteristics}

Table 1 shows the demographic characteristics of the participants in the study. Almost two-thirds (61.3\%) were women, one-quarter $(23.4 \%)$ were illiterate and the majority (65.6\%) were aged between 40 and 59 .

Table 2 illustrates the clinical characteristics, healthcare provider and health insurance status of the people in the sample. The average duration of T2D was $8.1 \pm 6.7$ years (mean $\pm \mathrm{sd}$ ), and $36.7 \%$ of the participants had been diagnosed within the previous five years. The majority (80.3\%) of participants had a family history of T2D, and $80.7 \%$ were non-smokers. The average BMI was $31.3 \pm 7.3$ (mean $\pm \mathrm{sd}$ ), and $56.5 \%$ of the participants had obesity $(\mathrm{BMI} \geq 30)$. Around half $(53.3 \%)$ of the participants had hypertension, and almost all (90.6\%) had dyslipidaemia. Good blood glucose control, which guidelines consider to be glycated haemoglobin $\left(\mathrm{HbA}_{1 \mathrm{c}}\right)$ below $7 \%$ for T2D $[2,28]$, was achieved by half $(52.6 \%)$ of the participants. Conversely, $47.4 \%$ were not in good control, and a remarkable proportion of the participants (20.9\%) had an $\mathrm{HbA}_{1 \mathrm{c}}$ above $9 \%$. The majority of the participants had been seen at a primary care centre (88.5\%), and $26.8 \%$ had been seen at a public hospital. Almost all (91.1\%) of the participants had no health insurance.

Table 1 Demographic characteristics of study participants $(N=628)$

\begin{tabular}{llll}
\hline Patient characteristics & & N & $\%$ \\
\hline Gender & Male & 243 & 38.7 \\
& Female & 385 & 61.3 \\
Education level & Illiterate & 146 & 23.4 \\
& Primary school & 111 & 17.8 \\
& Intermediate school & 105 & 16.8 \\
& Secondary school & 157 & 25.2 \\
& Higher education & 105 & 16.8 \\
Age & 20-39 & 52 & 8.3 \\
& $40-59$ & 412 & 65.6 \\
& $60-64$ & 164 & 26.1 \\
\hline
\end{tabular}

Table 2 Clinical characteristics, healthcare provider and health insurance status of study participants ( $N=628$ unless otherwise stated)

\begin{tabular}{|c|c|c|c|}
\hline $\begin{array}{l}\text { Patient } \\
\text { characteristics }\end{array}$ & & $\mathrm{N}$ & $\%$ \\
\hline \multirow[t]{4}{*}{ Duration of T2D $(N=619)$} & $<5$ years & 227 & 36.7 \\
\hline & $5-10$ years & 163 & 26.3 \\
\hline & $11-20$ years & 173 & 27.9 \\
\hline & $>20$ years & 56 & 9.0 \\
\hline \multirow[t]{2}{*}{ Family history of T2D } & Yes & 504 & 80.3 \\
\hline & No & 124 & 19.7 \\
\hline \multirow[t]{3}{*}{$\mathrm{BMI}(N=621)$} & $<25$ & 102 & 16.4 \\
\hline & $25-29$ & 168 & 27.1 \\
\hline & $\geq 30$ & 351 & 56.5 \\
\hline \multirow[t]{2}{*}{ Hypertension } & Yes & 335 & 53.3 \\
\hline & No & 293 & 46.7 \\
\hline \multirow[t]{2}{*}{ Dyslipidaemia } & Yes & 569 & 90.6 \\
\hline & No & 59 & 9.4 \\
\hline \multirow[t]{4}{*}{$\mathrm{HbA}_{1 c}(\mathrm{~N}=622)$} & $<7 \%$ & 327 & 52.6 \\
\hline & $7-8 \%$ & 95 & 15.3 \\
\hline & $8-9 \%$ & 72 & 11.6 \\
\hline & $>9 \%$ & 128 & 20.6 \\
\hline \multirow[t]{3}{*}{ Smoking status ( $N=623$ ) } & Smoker & 82 & 13.2 \\
\hline & Non-smoker & 503 & 80.7 \\
\hline & Ex-smoker & 38 & 6.1 \\
\hline \multirow[t]{4}{*}{ Healthcare provider } & Public hospital & 168 & 26.8 \\
\hline & Primary care centre & 556 & 88.5 \\
\hline & Private hospital & 60 & 9.6 \\
\hline & Private clinic & 28 & 4.5 \\
\hline \multirow[t]{2}{*}{ Health insurance } & Yes & 56 & 8.9 \\
\hline & No & 572 & 91.1 \\
\hline
\end{tabular}

T2D type 2 diabetes, $B M I$ body mass index, $H b A_{1 c}$ glycated haemoglobin

\section{Complication status of study participants}

Table 3 shows the complication status of the participants. The results showed that diabetes-related complications were common: almost half of the participants (43.4\%) had at least one complication, $38.5 \%$ had microvascular complications, $14.2 \%$ had macrovascular complications, $9.2 \%$ had both micro- and macrovascular complications, and $34.2 \%$ had either micro- or macrovascular complications.

Table 3 Complication status of study participants $(N=628)$

\begin{tabular}{lll}
\hline Complication status & $\mathrm{N}$ & $\%$ \\
\hline No complications & 355 & 56.6 \\
Microvascular complications & 242 & 38.5 \\
Macrovascular complications & 89 & 14.2 \\
Either micro- or macrovascular complications & 215 & 34.2 \\
Both micro- and macrovascular complications & 58 & 9.2 \\
\hline
\end{tabular}




\section{Healthcare costs attributable to T2D according to resource categories}

Table 4 shows the use of main resource categories by participants, Table 5 demonstrates the costs of these resources extrapolated to the entire T2D population living in Bahrain and Fig. 1 illustrates the relative distribution of cost by resource.

Of the 628 people in the sample, almost one in five (19.3\%) were admitted to hospital during this one-year period. Annual costs due to admissions amounted to 690 BHD (1831 USD) for each patient and 62.2 million BHD (165.1 million USD) for all people with T2D living in Bahrain and were by far the largest expenditure, accounting for $59.4 \%$ of the total costs of T2D. Procedures which covered cardiac catheterisation, laser treatment and cataract surgery were performed on $12.3 \%$ of the participants. The annual cost of the procedures amounted to 173 BHD (459 USD) for each patient and 15.6 million BHD (41.4 million USD) for the entire T2D population, constituting $14.9 \%$ of the total costs. $88.2 \%$ of the participants were outpatients (OP) (GP and secondary care visits), and laboratory tests were conducted on the same share of participants. The annual cost of OP visits was $101 \mathrm{BHD}$ (268 USD), and the cost of laboratory tests was 82 BHD (218 USD) for each patient, corresponding to 9.1 and 7.4 million BHD respectively (24.2 and 19.6 million USD) for the T2D population. This represented 8.7 and $7.1 \%$ respectively of the total

Table 4 Use of main resource categories among study participants $(N=628)$

\begin{tabular}{llll}
\hline Main resources & & $\mathrm{N}$ & $\%$ \\
\hline Admissions & Yes & 121 & 19.3 \\
& No & 507 & 80.7 \\
Procedures & Yes & 77 & 12.3 \\
& No & 551 & 87.7 \\
Outpatient visits & Yes & 554 & 88.2 \\
& No & 74 & 11.8 \\
Laboratory tests & Yes & 554 & 88.2 \\
& No & 74 & 11.8 \\
Oral antidiabetic medicine & Yes & 561 & 89.3 \\
& No & 67 & 10.7 \\
Other oral medicine to treat comorbidities & Yes & 447 & 71.2 \\
& No & 181 & 18.8 \\
Insulin and other injectables & Yes & 148 & 23.6 \\
& No & 480 & 76.4 \\
Self-monitoring & Yes & 187 & 29.8 \\
& No & 441 & 70.2 \\
\hline
\end{tabular}

Procedures covers cardiac catheterisation, laser treatment and cataract surgery; Outpatient visits covers primary and secondary care; Other oral medicine covers blood pressure-lowering medicine and lipid-lowering medicine; Self-monitoring covers lancets and strips cost. Almost one in four participants (23.6\%) used insulin and other injectables, $89.3 \%$ used oral antidiabetic medicine and $71.2 \%$ used oral medicine to treat comorbidities such as hypertension and hyperlipidaemia. The relative cost of all medicines combined was below $10 \%$. Insulin and other injectable antidiabetic medicine accounted for $3.7 \%$, or 42 BHD (111 USD), for each patient, and 3.8 million BHD (10.1 million USD) for the T2D population annually. The annual cost fraction of oral antidiabetic medicine was $4.2 \%$ and accounted for 49 BHD (130 USD) for each patient and 4.4 million BHD (11.7 million USD) for all people in Bahrain with T2D. Other oral medicines, including blood pressureand lipid-lowering agents, made up $1.8 \%$ of annual T2D costs: 21 BHD (56 USD) for each patient and 1.9 million BHD (5.0 million USD) for all the people with T2D in Bahrain. Of the 628 participants, $29.8 \%$ monitored their blood glucose. The annual cost of lancets and strips for self-monitoring of blood glucose was 2 BHD (5 USD) for each patient and 0.2 million BHD (0.5 million USD) for all the people with T2D in Bahrain, accounting for a small fraction $(0.2 \%)$ of the total costs.

\section{Healthcare costs attributable to T2D according to complication status}

Figure 2 illustrates that the more severe the complications are, the greater the cost burden is. The figure relates the costs to the average healthcare spend per person living in Bahrain, which was retrieved from the WHO global health expenditure atlas and was used for comparative purposes [29].

Figure 3 demonstrates the relative distribution of total T2D costs according to complication status and the number of patients. The annual overall treatment cost of T2D for each patient was almost three times more than for a person without T2D [29] (1162 versus 372 BHD (3084 versus 987 USD)). The annual treatment costs of T2D increased progressively with the severity of the complications - exceeding seven times more than for people without T2D and three times more than for people with T2D without complications. It is evident that $9 \%$ of people with T2D account for $21 \%$ of the treatment costs due to costly diabetes-related complications.

\section{Healthcare costs attributable to T2D in Bahrain}

Figure 4 illustrates the extrapolated direct medical costs of T2D in Bahrain compared with total health expenditure and $\mathrm{MOH}$ expenditure in Bahrain in 2015. According to the Bahrain Pharmaceuticals and Healthcare Report, the total health expenditure in Bahrain for 2015 was 686 million BHD, equivalent to 1.821 billion USD [30]. Thus, based on this study, the direct medical costs of T2D constituted $15.3 \%$ of the total health expenditure. According to the $\mathrm{MOH}$, the healthcare budget 
Table 5 Annual direct medical costs attributable to T2D according to main resource categories among study participants in Bahrain

\begin{tabular}{|c|c|c|c|c|}
\hline & For each patient & Total population & For each patient & Total population \\
\hline & $\begin{array}{l}\text { BHD } \\
(95 \% \mathrm{Cl}) \\
\end{array}$ & $\begin{array}{l}\text { USD } \\
(95 \% \mathrm{Cl})\end{array}$ & $\begin{array}{l}\text { Million BHD } \\
(95 \% \mathrm{Cl})\end{array}$ & $\begin{array}{l}\text { Million USD } \\
(95 \% \mathrm{Cl})\end{array}$ \\
\hline Admissions & $\begin{array}{l}690 \\
(485-895)\end{array}$ & $\begin{array}{l}1831 \\
(1287-2374)\end{array}$ & $\begin{array}{l}62.2 \\
(43.7-80.6)\end{array}$ & $\begin{array}{l}165.0 \\
(116.0-214.0)\end{array}$ \\
\hline Procedures & $\begin{array}{l}173 \\
(122-225)\end{array}$ & $\begin{array}{l}460 \\
(323-598)\end{array}$ & $\begin{array}{l}15.6 \\
(11.0-20.3)\end{array}$ & $\begin{array}{l}41.5 \\
(29.1-53.9)\end{array}$ \\
\hline Outpatient visits & $\begin{array}{l}101 \\
(94-108)\end{array}$ & $\begin{array}{l}269 \\
(250-288)\end{array}$ & $\begin{array}{l}9.1 \\
(8.5-9.8)\end{array}$ & $\begin{array}{l}24.2 \\
(22.5-26.0)\end{array}$ \\
\hline Laboratory tests & $\begin{array}{l}82 \\
(75-89)\end{array}$ & $\begin{array}{l}218 \\
(200-235)\end{array}$ & $\begin{array}{l}7.4 \\
(6.8-8.0)\end{array}$ & $\begin{array}{l}19.6 \\
(18.0-21.2)\end{array}$ \\
\hline Oral antidiabetic medicine & $\begin{array}{l}49 \\
(46-51)\end{array}$ & $\begin{array}{l}130 \\
(122-137)\end{array}$ & $\begin{array}{l}4.4 \\
(4.2-4.6)\end{array}$ & $\begin{array}{l}11.7 \\
(11.0-12.3)\end{array}$ \\
\hline Insulin and other injectables & $\begin{array}{l}42 \\
(34-51)\end{array}$ & $\begin{array}{l}113 \\
(91-134)\end{array}$ & $\begin{array}{l}3.8 \\
(3.1-4.6)\end{array}$ & $\begin{array}{l}10.2 \\
(8.2-12.1)\end{array}$ \\
\hline Other oral medicine & $\begin{array}{l}21 \\
(10-24)\end{array}$ & $\begin{array}{l}57 \\
(49-65)\end{array}$ & $\begin{array}{l}1.9 \\
(1.7-2.2)\end{array}$ & $\begin{array}{l}5.1 \\
(4.4-5.8)\end{array}$ \\
\hline Self-monitoring & $\begin{array}{l}2 \\
(945-1379)\end{array}$ & $\begin{array}{l}6 \\
(4-9)\end{array}$ & $\begin{array}{l}0.2 \\
(0.13-0.3)\end{array}$ & $\begin{array}{l}0.56 \\
(0.34-0.78)\end{array}$ \\
\hline Total costs ${ }^{a}$ & $\begin{array}{l}1162 \\
(945-1379)\end{array}$ & $\begin{array}{l}3084 \\
(2507-3659)\end{array}$ & $\begin{array}{l}104.7 \\
(85.1-124.2)\end{array}$ & $\begin{array}{l}277.8 \\
(225.9-329.7)\end{array}$ \\
\hline
\end{tabular}

Self-monitoring covers lancets and strips; Oral medicine covers oral antidiabetic medicine, blood pressure-lowering medicine and lipid-lowering medicine; Procedures covers cardiac catheterisation, laser treatment and cataract surgery; M: million

${ }^{a}$ Due to rounding, some totals may not correspond to the sum of the separate figures

was 334 million BHD (887 million USD) in 2015 [31]. Furthermore, general government health expenditure as a proportion of total health expenditure was $70.2 \%$ [32]. Thus, the direct medical costs attributable to T2D accounted for $22.0 \%$ of the total MOH expenditure (Fig. 4). Furthermore, the direct medical costs constituted 0.89\% of GDP in 2015.

\section{Indirect costs attributable to T2D in Bahrain}

Based on information collected through the participants' questionnaire, the average annual absenteeism due to T2D for each patient was 0.55 . As the average wage in
Bahrain is 24.9 BHD (66.1 USD) per day [26], the total indirect costs due to absenteeism were approximately 1.23 million BHD (3.26 million USD).

The absolute and relative distribution of the direct medical costs and indirect costs is shown in Table 6 and illustrates that direct medical costs account for the large majority of the total costs [33].

\section{Discussion}

This study is the first to document the healthcare costs of T2D in Bahrain. The direct medical costs of T2D and

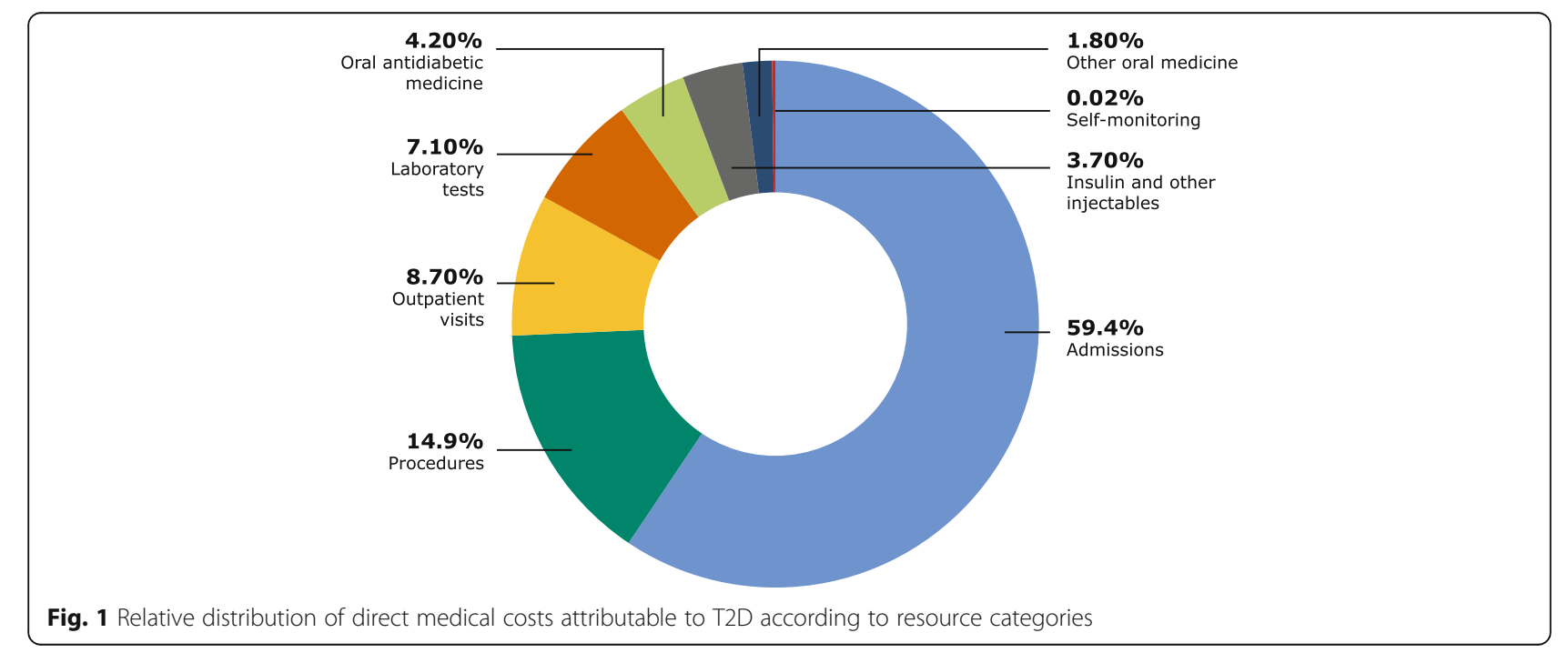




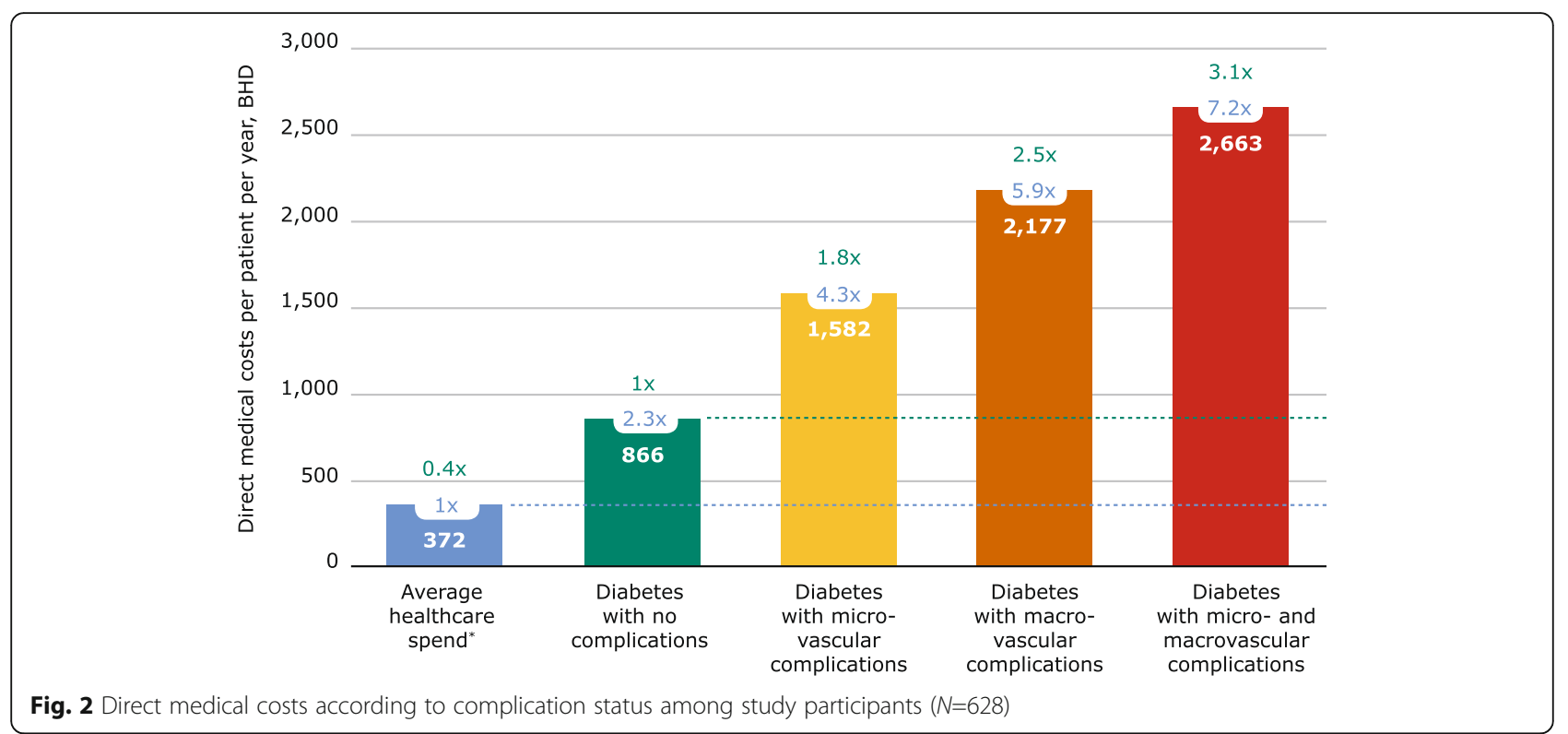

its related complications were 104.7 million BHD (277.9 million USD) in 2015. The serious financial burden of diabetes is obvious, as people with diabetes require 2-3 times the health resources of people without diabetes [34].

This study confirms that the direct health expenditure for a person with T2D was 3.1 times higher than the average costs for a person without T2D. Furthermore, it clearly illustrates that the direct medical costs attributable to T2D increase with the presence of diabetesrelated complications. These findings concur with results from similar studies in other countries that show that diabetes-related complications drive diabetes-related healthcare costs $[12,13,15,35-37]$. Only a relatively small fraction of the participants in this study had developed both micro- and macrovascular complications. This may be due to the fact that very advanced cases of T2D are referred to specialised secondary healthcare diabetes clinics and thus would not have been recruited to this study. However, even though the group with both micro- and macrovascular complications was relatively small, it accounted for a large proportion of the total
T2D expenditure. The primary factor driving increased costs for complications is the requirement for hospitalisation $[15,36,37]$. This shows that hospital admission is by far the most expensive single resource, consuming the largest share of the healthcare costs used to treat T2D, even though a relatively small proportion of patients use this resource. In other words, $20 \%$ of the patients consumed $60 \%$ of the direct medical costs attributable to T2D due to admissions. The proportion of admission costs is significantly higher than documented in other countries where it is on average $30 \%[12,13,15,35-37]$. This may indicate that there is an opportunity to increase secondary prevention in Bahrain and prevent or delay the onset of serious and expensive T2D-related complications.

The risk of developing serious and expensive complications increases with diabetes duration and higher $\mathrm{HbA}_{1 \mathrm{c}}$ $[9,38]$. Studies have shown that blood glucose control is often poor in countries in the MENA region [19, 39-41]. A chi-squared test revealed that in this study the number and severity of complications increased with higher $\mathrm{HbA}_{1 \mathrm{c}}$ $(p<0.05)$. Since blood glucose is an important factor in
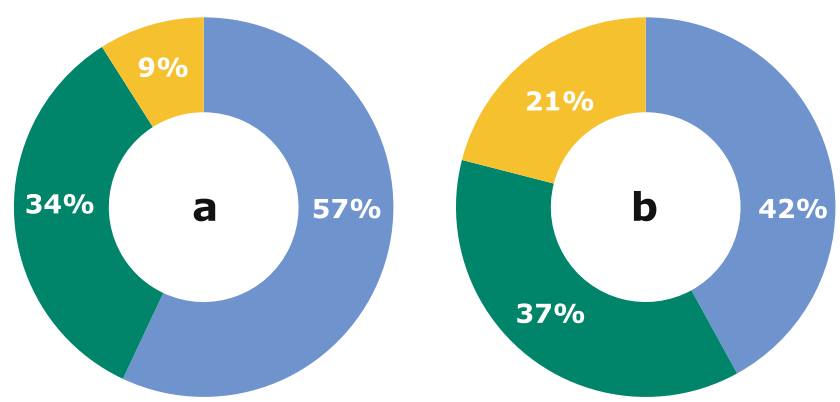

No

complications

Either micro- or macrovascular complications

Both micro- and macrovascular complications

Fig. 3 Relative distribution of patients (a) and diabetes-attributable costs (b) according to complication status 




Fig. 4 Direct medical costs of T2D from this study compared with total health and Ministry of Health expenditure in Bahrain, 2015

the development of complications [9], there is great benefit in lowering $\mathrm{HbA}_{1 \mathrm{c}}$ to achieve the official $\mathrm{HbA}_{1 \mathrm{c}}$ treatment target $[9,28,42]$. In this study, approximately one-third of patients had an $\mathrm{HbA}_{1 \mathrm{c}}$ above $8 \%$, which the IDF's guidelines describe as "unacceptably high" [42] and which is the point at which the risk of complications increases significantly [9]. An additional beneficial approach is to increase attempts to detect and diagnose people with T2D early, in order to initiate optimal treatment during the asymptomatic phase of the condition, to reduce the risk of complications as the condition progresses [43]. Harris et al. documented that a relatively long asymptomatic period of 9-12 years is often the case with T2D [44]. The IDF estimates that up to $49 \%$ of people with T2D in the MENA region remain undiagnosed and that the proportion of people with undiagnosed T2D in Bahrain is 38\% [2].

For the majority of people with T2D, the primary source of care is their GP, as was the case in this study. However, due to the complexity of managing T2D, primary care providers often maintain patients at suboptimal glycaemic levels, even though there is a willingness to intensify treatment $[40,41,45]$. In this study, just half of the patients achieved the recommended $\mathrm{HbA}_{1 \mathrm{c}}$ target. This suggests that there is a likely advantage to empowering GPs to improve treatment quality $[41,45]$.

Bommer et al., based on epidemiologic and economic data from 184 countries, estimated that the global cost of diabetes in 2015 was 1.31 trillion USD [46], which was $1.8 \%$ of global GDP. They noted that indirect costs accounted for $34.7 \%$ of the total burden [46]. They found that the direct medical costs of diabetes represented $0.84 \%$ of GDP in the MENA region, with total costs, including indirect costs, accounting for $1.3 \%$ of the region's GDP. Since T2D makes up the vast majority of diabetes cases worldwide [2], these figures can be taken to be largely representative of T2D. This concurs with our finding of the direct medical costs of T2D representing 0.89\% of Bahrain's GDP.

This study has several limitations, which may have contributed to underestimating the treatment cost of T2D. Firstly, people with T2D who were not associated with any clinics, or very advanced cases of T2D referred to secondary clinics, were not included in this study. Secondly, the diabetes prevalence used in this study is based on a survey from 2007 [20]. Other studies indicate that the diabetes prevalence in Bahrain may be substantially underestimated [47]. If the diabetes burden in Bahrain is expected to follow the same development as in other countries, it would have increased since then. Thirdly, treatment costs are expected to rise with increasing age [48], and few patients above the age of 60 were included in this study compared with the survey [20]. Non-medical costs, such as transportation, were not included in this study. It was assumed that in a small country such as Bahrain, transportation would represent an insignificant cost factor, due to an infrastructure where all health centres are located within a 20-min drive of all residents' homes and of a main hospital.

The human capital approach may misestimate the productivity loss by excluding unpaid work, applying an average salary which varies depending on the type of profession, not accounting for presenteeism (decreased productivity due to ill health while at work) and not including productivity loss due to mortality.

We therefore assume that the estimates illustrated by this study are conservative. However, it is our hope that

Table 6 Absolute and relative distribution of direct medical and indirect costs attributable to T2D in Bahrain

\begin{tabular}{lllll}
\hline & Million BHD & Million USD & \% of total cost & \% of GDP [33] \\
\hline Direct medical costs & 104.70 & 277.89 & $98.8 \%$ & $0.89 \%$ \\
Indirect costs & 1.23 & 3.26 & $1.2 \%$ & $0.01 \%$ \\
Total costs & 105.93 & 281.15 & $100 \%$ & $0.9 \%$ \\
\hline
\end{tabular}

Bahrain GDP in 2015: 31.13 billion USD [33] 
the challenges of the T2D burden in Bahrain are clear, and that the results will guide decisions on future healthcare investments in T2D.

\section{Conclusion}

In conclusion, this study is the first of its kind to document the health-economic aspects of T2D in Bahrain. It shows that the costs of T2D and its complications constitute an enormous burden to Bahrain. This is not sustainable in the long run, and focusing on secondary prevention by optimising diabetes management and control, thereby reducing or eliminating the risk of disabling and expensive complications, has the greatest potential to counteract this.

\section{Supplementary information}

Supplementary information accompanies this paper at https://doi.org/10. 1186/s12913-019-4795-5.

Additional file 1. Diabetes impact in Bahrain questionnaire.

\section{Abbreviations}

BHD: Bahraini dinar; GCC: Gulf Cooperation Council; IDF: International Diabetes Federation; MENA: Middle East and North Africa; $\mathrm{MOH}$ : Ministry of Health; T2D: Type 2 diabetes; USD: United States dollar

\begin{abstract}
Acknowledgements
The authors would like to thank Dr. Waleed al Manee, undersecretary of the $\mathrm{MOH}$, who provided unlimited support with validating the data and publication; Dr. Manal Al-Alawi, assistant undersecretary of primary care at the $\mathrm{MOH}$, who provided unlimited support in validating the data and publication; and Dr. Maryam Al-Jalahma, CEO of NHRA Bahrain, who provided the support to facilitate the work process throughout the project. Writing support, interpretation and the critical review were provided by Last Mile and Malene Bagger (M Bagger Scientific Writing). The authors would also like to thank Dr. Maryam Al-Hajri, who contributed to the final review, and all the nursing teams and public health staff who were involved in collecting and entering the data.
\end{abstract}

\section{Authors' contributions}

ASA and RAS conceived the study, analysed and interpreted the data, and together with $\mathrm{CL}$ wrote the manuscript. All authors read and approved the final manuscript.

\section{Funding}

The authors wish to acknowledge Novo Nordisk for sponsoring the medical writing and for its support with the design, submission and publication of this manuscript. However, Novo Nordisk played no role in the actual collection or interpretation of the data.

\section{Availability of data and materials}

The datasets used and/or analysed during the current study are available from the corresponding author on reasonable request. The patient questionnaire is included as supplementary material.

\section{Ethics approval and consent to participate}

All participants were informed about the purpose of the study, and a written informed consent was obtained before it commenced. This study and the consent procedure were approved by the Ministry of Health of the Kingdom of Bahrain who is a member of the Research Ethics Committee Bahrain and the involved clinics.

\section{Consent for publication}

Not applicable

\section{Competing interests}

The authors declare that they have no competing interests.

\section{Author details}

${ }^{1}$ Ministry of Health, Manama, Kingdom of Bahrain. ${ }^{2}$ Associate professor, Arabian Gulf University, Manama, Kingdom of Bahrain. ${ }^{3}$ Last Mile, Holte, Denmark.

Received: 9 June 2019 Accepted: 29 November 2019

Published online: 05 December 2019

\section{References}

1. World Health Organization. Global report on diabetes. Geneva: World Health Organization; 2016.

2. International Diabetes Federation. IDF diabetes atlas, 8 ed. Brussels: International Diabetes Federation; 2017

3. American Diabetes Association. Diagnosis and classification of diabetes mellitus. Diabetes Care. 2012;35(Suppl 1):S64-71.

4. Maahs DM, West NA, Lawrence JM, Mayer-Davis EJ. Epidemiology of type 1 diabetes. Endocrinol Metab Clin. 2010;39(3):481-97.

5. Daneman D. Type 1 diabetes. Lancet. 2006;367(9513):847-58.

6. Evans J, Newton RW, Ruta DA, MacDonald TM, Morris AD. Socio-economic status, obesity and prevalence of type 1 and type 2 diabetes mellitus. Diabet Med. 2000:17(6):478-80.

7. Bruno G, Runzo C, Cavallo-Perin P, Merletti F, Rivetti M, Pinach S, Novelli G, Trovati M, Cerutti F, Pagano G. Incidence of type 1 and type 2 diabetes in adults aged 30-49 years: the population-based registry in the province of Turin, Italy. Diabetes Care. 2005;28(11):2613-9.

8. Holman N, Young B, Gadsby R. Current prevalence of type 1 and type 2 diabetes in adults and children in the UK. Diabet Med. 2015:32(9):1119-20.

9. Stratton IM, Adler Al, Neil HA, Matthews DR, Manley SE, Cull CA, Hadden D, Turner RC, Holman RR. Association of glycaemia with macrovascular and microvascular complications of type 2 diabetes (UKPDS 35): prospective observational study. BMJ. 2000;321(7258):405-12.

10. Deshpande AD, Harris-Hayes M, Schootman M. Epidemiology of diabetes and diabetes-related complications. Phys Ther. 2008;88(11):1254-64.

11. Seuring $T$, Archangelidi $O$, Suhrcke M. The economic costs of type 2 diabetes: a global systematic review. Pharmacoeconomics. 2015;33(8):811-31.

12. American Diabetes A. Economic costs of diabetes in the U.S. in 2017. Diabetes Care. 2018:41(5):917-28.

13. Charbonnel B, Simon D, Dallongeville J, Bureau I, Dejager S, Levy-Bachelot L, Gourmelen J, Detournay B. Direct medical costs of type 2 diabetes in France: an insurance claims database analysis. Pharmacoecon Open. 2018; 2(2):209-19.

14. Marcellusi A, Viti R, Mecozzi A, Mennini FS. The direct and indirect cost of diabetes in Italy: a prevalence probabilistic approach. Eur J Health Econ. 2016;17(2):139-47.

15. Al-Maskari F, El-Sadig M, Nagelkerke N. Assessment of the direct medical costs of diabetes mellitus and its complications in the United Arab Emirates. BMC Public Health. 2010;10(1):679.

16. Loeppke R, Taitel M, Haufle V, Parry T, Kessler RC, Jinnett K. Health and productivity as a business strategy: a multiemployer study. J Occup Environ Med. 2009:51(4):411-28

17. Breton MC, Guenette L, Amiche MA, Kayibanda JF, Gregoire JP, Moisan J. Burden of diabetes on the ability to work: a systematic review. Diabetes Care. 2013;36(3):740-9.

18. Sherif S, Sumpio BE. Economic development and diabetes prevalence in MENA countries: Egypt and Saudi Arabia comparison. World J Diabetes. 2015:6(2):304-11.

19. Khattab M, Khader YS, Al-Khawaldeh A, Ajlouni K. Factors associated with poor glycemic control among patients with type 2 diabetes. J Diabetes Complicat. 2010;24(2):84-9.

20. Ministry of Health Kingdom of Bahrain. National non-communicable diseases risk factor survey 2007. Manama: Ministry of Health Kingdom of Bahrain; 2009

21. International Diabetes Federation. IDF diabetes atlas, 7th edn. Brussels: International Diabetes Federation; 2015

22. International Diabetes Federation. IDF diabetes atlas, 2 ed. Brussels: International Diabetes Federation; 2003.

23. Al-Rubeaan K. The impact of diabetes mellitus on health and economy of gulf cooperation council countries. Diabetes Manag. 2014;4(4):381-90. 
24. Ministry of Health Kingdom of Bahrain. Internal document. Supportive services directorate. Riyadh: Ministry of Health; 2015.

25. Grosse SD, Krueger KV. The income-based human capital valuation methods in public health economics used by forensic economics. J Forensic Econ. 2011;22(1):43-57.

26. Labour Market Regulatory Authority. Labour market indicators - core data. Table 21. Kingdom of Bahrain: Labour Market Regulatory Authority; 2018.

27. Ministry of Health Kingdom of Bahrain. Prevalence of NCD and its risk factors among expatriate workers at Al-Razi Health Centre in Bahrain. Manama: Ministry of Health Kingdom of Bahrain; 2011.

28. Ministry of Health Kingdom of Bahrain. Guideline for management of type 2 diabetes mellitus in primary care settings and outpatient clinics in the Kingdom of Bahrain. Manama: Ministry of Health; 2014.

29. World Health Organization. WHO global health expenditure atlas. Geneva: WHO; 2014. p. 2014.

30. BMI Research. Bahrain pharmaceuticals \& healthcare report. Executive summary. London: BMI Research; 2018.

31. MOH statistics. Health statistics of 2015 [https://www.moh.gov.bh/Ministry/ Statistics?lang=en]

32. World Health Organization. Health profile 2015. Bahrain. Cairo: WHO Regional Office for the Eastern Mediterranean; 2017.

33. Data GDP (current US\$) 2015 [https://data.worldbank.org/country/bahrain].

34. American Diabetes A. Economic costs of diabetes in the U.S. in 2012. Diabetes Care. 2013;36(4):1033-46.

35. Alva ML, Gray A, Mihaylova B, Leal J, Holman RR. The impact of diabetesrelated complications on healthcare costs: new results from the UKPDS (UKPDS 84). Diabet Med. 2015;32(4):459-66.

36. Henriksson F, Agardh CD, Berne C, Bolinder J, Lonnqvist F, Stenstrom P, Ostenson CG, Jonsson B. Direct medical costs for patients with type 2 diabetes in Sweden. J Intern Med. 2000;248(5):387-96.

37. Sortso C, Green A, Jensen PB, Emneus M. Societal costs of diabetes mellitus in Denmark. Diabet Med. 2016;33(7):877-85.

38. Brownlee M. Biochemistry and molecular cell biology of diabetic complications. Nature. 2001;414(6865):813-20.

39. Al-Ubaidi BA, Al-Khadraji MA, Al-Hermi B. Measuring adherence rate to quality indicators for diabetes care identified by primary health care in Bahrain. Saudi Med J. 2014;35(9):975-80.

40. Whitford DL, Al-Anjawi HA, Al-Baharna MM. Impact of clinical inertia on cardiovascular risk factors in patients with diabetes. Prim Care Diabetes. 2014;8(2):133-8.

41. Shams N, Amjad S, Kumar N, Ahmed W, Saleem F. Drug non-adherence in type 2 diabetes mellitus; predictors and associations. J Ayub Med Coll Abbottabad. 2016;28(2):302-7.

42. International Diabetes Federation. Recommendations for managing type 2 diabetes in primary care, 2017. Brussels: International Diabetes Federation; 2017.

43. Herman WH, Ye W, Griffin SJ, Simmons RK, Davies MJ, Khunti K, Rutten GE, Sandbaek A, Lauritzen T, Borch-Johnsen K, et al. Early detection and treatment of type 2 diabetes reduce cardiovascular morbidity and mortality: a simulation of the results of the Anglo-Danish-Dutch study of intensive treatment in people with screen-detected diabetes in primary care (ADDITION-Europe). Diabetes Care. 2015;38(8):1449-55.

44. Harris MI, Klein R, Welborn TA, Knuiman MW. Onset of NIDDM occurs at least 4-7 yr before clinical diagnosis. Diabetes Care. 1992;15(7):815-9.

45. Sterzi D, Auziere S, Glah D, Markert Jensen M. Perceptions of general practitioners on initiation and intensification of type 2 diabetes injectable therapies. A quantitative study in the United Kingdom. Prim Care Diabetes. 2017;11(3):241-7.

46. Bommer C, Heesemann E, Sagalova V, Manne-Goehler J, Atun R, Barnighausen T, Vollmer S. The global economic burden of diabetes in adults aged 20-79 years: a cost-of-illness study. Lancet Diabetes Endocrinol. 2017;5(6):423-30.

47. Jassim G, Aloia A-A. The Epidemiologic Profile of Diabetes Mellitus among Attendees of Outpatient Clinics at Bahrain Defense Force Hospital: A CrossSectional Study. Journal of Global Diabetes \& Clinical Metabolism. 2017;2: 013.

48. Zhuo X, Zhang P, Barker L, Albright A, Thompson TJ, Gregg E. The lifetime cost of diabetes and its implications for diabetes prevention. Diabetes Care. 2014;37(9):2557-64.

\section{Publisher's Note}

Springer Nature remains neutral with regard to jurisdictional claims in published maps and institutional affiliations.

\section{Ready to submit your research? Choose BMC and benefit from:}

- fast, convenient online submission

- thorough peer review by experienced researchers in your field

- rapid publication on acceptance

- support for research data, including large and complex data types

- gold Open Access which fosters wider collaboration and increased citations

- maximum visibility for your research: over $100 \mathrm{M}$ website views per year

At BMC, research is always in progress.

Learn more biomedcentral.com/submissions 